\title{
A NOTIFICAÇÃO DOS INTERESSADOS EM AÇÕES COLETIVAS ENVOLVENDO DIREITOS INDIVIDUAIS HOMOGÊNEOS E SUA RELAÇÃO COM O ACESSO À JUSTIÇA
}

\author{
Márcia Maria Pires Carneiro ${ }^{1}$
}

RESUMO: O presente estudo tem por objetivo analisar a forma e efetividade da notificação feita aos interessados após a propositura de ações coletivas que visam a tutela de direitos individuais homogêneos. Para o alcance do objetivo a pesquisa iniciou contextualizando e diferenciando os direitos coletivos lato sensu e a sua relevância no cenário atual, ante o dinamismo nas relações sociais. Em seguida apresentou linhas gerais sobre o processo coletivo que visa tutelar os direitos individuais homogêneos, ingressando, posteriormente, na exposição sobre a forma de notificação dos interessados, demonstrando a inefetividade do modelo atual adotado e seu prejuízo ao acesso à justiça pelos interessados, à celeridade processual, ao contraditório efetivo e princípio da máxima efetividade do processo coletivo. Por fim, a pesquisa apresenta sugestões que podem ser adotadas pelo Poder Judiciário e, preferencialmente, pelo legislador ordinário para fazer com que os interessados tenham conhecimento acerca dos processos coletivos que discutem sobre seus direitos, permitindo um processo participativo e uma execução que realmente repare as lesões causadas.

Palavras-chave: Ações Coletivas. Direitos Individuais Homogêneos. Acesso à Justiça.

ABSTRACT: The present study aims to analyze the form and effectiveness of the notification made to the interested parties after the filing of collective actions aimed at the protection of homogeneous individual rights. In order to achieve the objective, the research started by contextualizing and differentiating collective lato sensu rights and their relevance in the current scenario, given the dynamism in social relations. Then he presented general lines on the collective process that aims to protect homogeneous individual rights, later entering the exhibition on the form of notification of interested parties, demonstrating the ineffectiveness of the current model adopted and its prejudice to access to justice by interested parties, to speed procedural, to the effective adversary and principle of maximum effectiveness of the collective process. Finally, the research presents suggestions that can be adopted by the Judiciary and, preferably, by the ordinary legislator to make interested parties aware of the collective processes that discuss their rights, allowing for a participatory process and an execution that really repairs the injuries caused.

\footnotetext{
I Acadêmica do curso de Direito da Universidade Estadual de Feira de Santana. E-mail: mm.pireso23@gmail.com.
} 
Keywords: Collective Actions. Homogeneous Individual Rights. Access to Justice.

\section{INTRODUÇÃO}

O reconhecimento dos direitos coletivos lato sensu possui uma grande relevância no mundo atual em razão das novas formas de organizações sociais e seus impactos. Todavia, apenas reconhecer esses direitos não basta para garanti-los, sendo necessária a adoção de medidas eficazes que protejam tais direitos, seja no âmbito judicial ou extrajudicial. No primeiro caso, faz-se necessário pensar em regras processuais que estejam em consonância com os princípios que regem nosso ordenamento jurídico e, ao mesmo tempo, que sejam eficientes e alcancem os fins almejados.

Diante dessa constatação, o presente trabalho visa analisar criticamente o método utilizado para cientificar os titulares dos direitos individuais homogêneos acerca da existência de ações coletivas discutindo temática do seu interesse, principalmente acerca da execução, onde eles podem liquidar diretamente e reparar os danos causados no caso concreto.

Mais precisamente, este trabalho tem como objetivos específicos: a) analisar se existe efetividade no tipo de notificação adotada em relação ao perfil comum da população brasileira; b) quais as implicações deste tipo de notificação na fase de liquidação e execução da sentença coletiva e c) se a medida adotada se mostra suficiente para impedir a massificação de ações individuais sobre a mesma temática.

O trabalho foi desenvolvido com base no estudo da legislação brasileira, em especial o Código de Defesa do Consumidor (Lei no 8.078/1990), bem como através de leitura de trabalhos jurídicos relacionados com a temática aqui discutida ou que poderiam contribuir para a construção da análise feita.

$\mathrm{Na}$ pesquisa documental, foram utilizadas jurisprudências de tribunais pátrios, principalmente os acórdãos proferidos pelo Supremo Tribunal Federal e pelo Superior Tribunal de Justiça, além de relatórios finais de pesquisas realizadas e divulgadas pelo Conselho Nacional de Justiça e pelo Instituto Pró-Livro.

Portanto, trata-se de uma pesquisa qualitativa, enquadrando-se no tipo de pesquisa jurídico-propositiva e jurídico-exploratória, questionando uma norma, expondo um problema com o escopo de apresentar soluções a serem aplicada no caso concreto. 


\section{BREVE EXPLANAÇÃO SOBRE OS DIREITOS COLETIVOS LATO SENSU}

Os chamados direitos fundamentais passaram a ser reconhecidos e positivados após uma série de acontecimentos e disseminação de ideias, tais como, a luta contra o absolutismo, as revoluções, os movimentos de independência de povos e concepções jusfilosóficas e se consolidando ao longo do tempo, não sendo possível precisar uma origem exata.

A doutrina majoritária costuma elencar tais direitos conforme as dimensões, sendo que a primeira está ligada aos direitos de liberdade - direitos ligados ao indivíduo e oponíveis principalmente contra a ingerência do Estado, impondo um dever de abstenção a segunda dimensão está ligada à igualdade material - direitos sociais, econômicos e culturais, gerando um dever prestacional ao Estado - e a terceira dimensão, relacionada à fraternidade ou solidariedade - com direitos transindividuais que buscam a proteção do gênero humano.

Existem doutrinadores como Paulo Bonavides que defendem a existência de mais duas dimensões, sendo a quarta, conforme o referido autor, ligada à democracia, informação e pluralismo e a quinta, através do direito à paz (BONAVIDES, 2006. p.571.572).

Não obstante a importância de cada uma dessas dimensões e direitos para a construção de um todo, neste trabalho nos interessa o estudo dos direitos transindividuais, sendo conceituado pelo ilustre Doutrinador Paulo Bonavides (BONAVIDES, 2006. p. 563564), como aqueles:

\footnotetext{
Dotados de altíssimo teor de humanismo e universalidade, os direitos da terceira geração tendem a cristalizar-se neste fim de século enquanto direitos que não se destinam especificamente à proteção dos interesses de um indivíduo, de um grupo, ou de um determinado Estado. Têm primeiro por destinatário o gênero humano mesmo, num momento expressivo de sua afirmação como valor supremo em termos de existencialidade concreta. Os publicistas e juristas já o enumeram com familiaridade, assinalando-lhe o caráter fascinante de coroamento de uma evolução de trezentos anos na esteira da concretização dos direitos fundamentais. (BONAVIDES, 2006. p. 563-4).
}

Não diferente das outras, a terceira dimensão de direitos fundamentais também foi fruto de um período de grandes transformações sociais, com bruscas mudanças na 
troca e disseminação de informações em razão do fenômeno da globalização, além do consumismo excessivo, dissociado de preocupações com as consequências e visando apenas o lucro dos fornecedores.

Diante desse cenário, surgiu à necessidade de proteger direitos que beneficiavam uma coletividade de pessoas determinadas ou indeterminadas e que estavam sem a tutela adequada.

Preocupado com os problemas enfrentados pelo Estado em sua função jurisdicional, o autor italiano Mauro Cappelletti, através do Projeto Florença, em colaboração com Bryant Garth, Nicolò Trocker e estudiosos de vários países, estudaram concretamente as barreiras que impediam a efetivação do acesso à Justiça, sistematizando essas constatações nas chamadas Ondas Renovatória em 1974/1975.

Dentre esses problemas, a segunda onda renovatória expôs a ineficácia da proteção dos direitos difusos e coletivos e a necessidade de adequação do processo, alertando os juristas de todo o mundo sobre as lacunas e deficiência do sistema processual para lidar com as violações em massa.

Para uma melhor compreensão acerca desse grandioso estudo, mostra-se interessante trazer transcrições de duas passagens da obra (CAPPELLETTI, 1989, p. 31 e 49):

O recente despertar de interesse em torno do acesso à justiça levou a três proposições básicas, pelo menos nos países do mundo ocidental. Tendo início em 1965, estes posicionamentos emergiram mais ou menos em sequência cronológica. Podemos afirmar que a primeira solução para o acesso - a primeira 'onda' desse movimento novo - foi a 'assistência judiciária'; a segunda dizia respeito às reformas tendentes a proporcionar 'representação jurídica para os interesses difusos', especialmente nas áreas da proteção ambiental e do consumidor; e o terceiro - e mais recente - é o que nos propomos a chamar simplesmente 'enfoque de acesso à justiça' porque inclui os posicionamentos anteriores, mas vai muito além deles, representando, dessa forma, uma tentativa de atacar as barreiras ao acesso de modo mais articulado e compreensivo."

(...)

O segundo grande movimento no esforço de melhorar o acesso à justiça enfrentou o problema da representação dos interesses difusos, assim chamados os interesses coletivos ou grupais, diversos daqueles dos pobres. Nos Estados Unidos, onde esse mais novo movimento de reforma é ainda provavelmente mais avançado, as modificações acompanharam o grande qüinqüênio de preocupações e providências na área da assistência jurídica. (CAPPELLETTI, 1989, p. 31 e 49).

O mencionado estudo representa um grande marco no campo do Direito, expondo

grandes obstáculos existentes no acesso à Justiça e influenciando os legisladores a 
criarem leis para afastar os obstáculos e aprimorar os procedimentos adotados, contemplando as novas formas de tutela.

No Brasil, observou uma demora em editar leis para regulamentar as demandas coletivas em razão do pensamento doutrinário e jurisprudencial da época, conforme se pode observar a partir da leitura do artigo 97 do Código Civil de 1917, in verbis:

Art. 76. Para propor ou contestar uma ação, é necessário ter legítimo interesse econômico ou moral.

Parágrafo único: o interesse moral só autoriza a ação quando toque diretamente ao autor, ou à sua família.

$\mathrm{O}$ artigo refletia o posicionamento que prevalecia e retratava a preocupação com as lides unitárias, ignorando as mudanças da sociedade e permitindo a violação dos direitos transindividuais que não era sanada por meras ações individuais. Obviamente, o entendimento foi seguido nos Códigos Processuais promulgados em 1939 e 1973.

Muito embora o cenário desfavorável, o legislador brasileiro editou a Lei de Ação Popular no 4.717 em 29 de junho de 1965, permitindo a qualquer cidadão a sua propositura para anular ato lesivo ao patrimônio público, à moralidade administrativa, ao patrimônio histórico e cultural e ao meio ambiente.

Outras leis importantes foram surgindo, como a Lei que disciplina a Política Nacional do Meio Ambiente (Lei no 6.938) e a Lei Orgânica do Ministério Público que permitiu sua legitimação para propositura de ações coletivas. Cabe destacar ainda a Lei de Ação Civil Pública (Lei no 7.347/1985) que foi considerada por muitos como fruto das Ondas Renovatórias.

A Constituição Federal promulgada em 1988 também representou um grande marco da sistemática coletiva, trazendo um rol de direito exemplificativos abarcando tanto direitos individuais quanto coletivos, além de prever em seu texto diversas ações importantes para a tutela coletiva.

Em 1990, outra grande evolução deu-se com a chegada do Código de Defesa do Consumidor, trazendo conceituações e importantes regras processuais, como os efeitos da coisa julgada, a possibilidade de intervenção individual no processo coletivo, entre outros avanços.

Em relação à conceituação, o Código de Defesa do Consumidor esclareceu que os direitos difusos são aqueles transindividuais, com titulares indeterminados, ligados por 
circunstâncias de fato. A título de exemplo, pode-se citar a poluição de um rio ou ainda a contaminação do ar causado por determinada empresa, cujos prejuízos afetam um número indeterminado de pessoas e que não estão ligadas por nenhum vínculo anterior, lesionado o direito ao meio ambiente saudável e equilibrado. ${ }^{2}$

Nas palavras de Ada Pellegrini Grinover (GRINOVER, 1984, p. 30-I), os direitos difusos:

(...) compreende interesses que não encontram apoio em uma relação base bem definida, reduzindo-se o vínculo entre as pessoas a fatores conjunturais ou extremamente genéricos, a dados de fato freqüentemente acidentais ou mutáveis: habitar a mesma região, consumir o mesmo produto, viver sob determinadas condições sócio-econômicas, sujeitar-se a determinados empreendimentos, etc. (GRINOVER, 1984, p. 30-3i).

A principal diferença na conceituação dos direitos difusos e dos direitos coletivos strictu sensu é a ligação entre os titulares, tendo em vista que nestes existe uma relação jurídica base que liga os beneficiários entre si ou com a parte contrária, servindo como ilustração o aumento abusivo da mensalidade dos alunos de determinada escola ou dos beneficiários de determinado plano de saúde.

Mesmo não sendo um direito essencialmente coletivo, o legislador ordinário trouxe regulamentações acerca dos direitos individuais homogêneos, elegendo-o como coletivo, conceituando-os como aqueles que possuem uma origem comum.

Para uma melhor compreensão acerca da expressão do significado de origem comum e evitar confusões, mostra-se interessante transcrever a lição do jurista Leonardo Roscoe Bessa, mencionado pelo Professor Hermes Zaneti Júnior (ZANETI JÚNIOR apud BESSA, op. cit., p. 388-389):

'Origem comum' não significa, necessariamente, uma unidade factual e temporal. As vítimas de uma publicidade enganosa veiculada por vários órgãos de imprensa e em repetidos dias ou de um produto nocivo à saúde adquirido por vários consumidores em um largo espaço de tempo e em várias regiões têm, como causa de seus danos, fatos com homogeneidade tal que os tornam a 'origem comum' de todos eles.”, ou seja, o que têm em comum é a procedência, e a gênese na conduta comissiva ou omissiva da parte contrária. (ZANETI JÚNIOR apud BESSA, op. cit., p. 388-389).

A criação jurídica dos direitos individuais homogêneos e a sua tutela através das ações coletivas mostram-se extremamente relevantes, tendo em vista que impede, em tese, a massificação de ações individuais com sentenças de conteúdo variáveis, e proporciona

\footnotetext{
${ }^{2}$ Art. 8I, § único, I do CDC.
} 
uma paridade de armas, dado que os direitos são defendidos por um ente legitimado e não por seu titular que, muitas vezes, releva-se hipossuficiente.

\section{DO MICROSSISTEMA DA TUTELA COLETIVA}

O Ordenamento Jurídico Brasileiro possui vários tipos de microssistemas, que, conforme divisão proposta pelo Professor Fabrício Bastos ${ }^{3}$, podem ser subdivididos, ao menos, em três categorias, são elas: parte integrante de uma única lei - v.g. a lei do inquilinato, Estatuto da Criança e Adolescente, Estatuto do Torcedor-, parte integrante de leis esparsas - microssistema da tutela coletiva - e parte integrante de um código - v.g. Microssistema de padronização de julgamento contido no Código de Processo Civil.

Até o presente momento não existe um Código de Processo Coletivo ${ }^{4}$, todavia, uma pequena parcela da doutrina defende que o Código de Defesa do Consumidor poderia ser assim considerado. Existem ainda aqueles doutrinadores que defendem a existência de um núcleo essencial do Microssistema de Tutela Coletiva, composto pelo Código de Defesa do Consumidor e pela Lei de Ação Civil Pública (Lei no 7.347/1985).

Independente da qualificação atribuída, é inegável que o Código Consumerista serve como norteador do Microssistema e traz regulamentações importantes, como as hipóteses de coisa julgada das sentenças proferidas em ações coletivas separadas por cada tipo de direito coletivo lato sensu. ${ }^{5}$

Discute-se ainda acerca da aplicação do Código de Processo Civil às tutelas coletivas, tendo em vista que foi criado, em regra, para disciplinar os procedimentos individuais. A despeito disso, dispõe acerca das regras processuais e, consequentemente, causa reflexos nas demandas coletivas. A doutrina não está pacificada quanto a essa aplicação nos processos coletivos, razão pela qual surgiram três principais correntes.

\footnotetext{
${ }^{3}$ Explicação lançada em aula do curso de Pós-Graduação em Processo Civil da Escola Superior da Advocacia Nacional, em seu módulo destinado à tutela coletiva.

4 Em 2002, Antonio Gidi editou uma proposta de Código de Processo Civil Coletivo, submetendo-o à Câmara dos Deputados e ao Ministério da Justiça, surgindo o Projeto de Lei nº 5.139/20o9, sendo, porém, rejeitado no mérito pelos congressistas recebeu parecer favorável quanto à constitucionalidade, sendo rejeitado no mérito, todavia, sob os fundamentos que, caso aprovado, ensejaria tratamento desigual entre as partes nos processos coletivos; conferiria poderes excessivos ao Ministério Público e à Defensoria Pública; ensejaria insegurança jurídica e estimularia o ajuizamento de ações coletivas temerárias. (VASCONCELOS ROQUE, 2013, p. 55).

${ }^{5}$ Art. Io3 e Art. Io4 do CDC.
} 
A primeira corrente - mais utilizada pela doutrina - defende que, inicialmente, deve ser aplicada a legislação específica que trata da matéria e, em sua ausência, deve ser aplicada as demais normas do microssistema da tutela coletiva. Por fim, defendem que, no caso da persistência da omissão, o Código de Processo Civil seja utilizado.

Noutro giro, uma segunda corrente doutrinária defende a utilização de uma ordem diferente, qual seja: a verificação da possibilidade de aplicação do Código de Defesa do Consumidor ou Lei de Ação Civil Pública e, caso não possa aplicá-las buscar a aplicação dentro do microssistema e posteriormente no Código de Processo Civil, considerando-o alheio ao microssistema da tutela coletiva.

Não menos importante, a terceira corrente, diversamente da anterior, defende que o Código de Processo Civil faz parte do microssistema da tutela coletiva e propõe a seguinte ordem de aplicação das normas: a utilização da norma própria da matéria discutida; não existindo ou sendo insuficiente, analisa se o Código de Defesa do Consumidor ou Lei de Ação Civil Pública pode sanar a omissão. Ainda assim, caso persista a lacuna, aplica-se qualquer outra norma compatível dentro do microssistema de tutela coletiva, incluindo o Código de Processo Civil.

Muitos criticam ainda que o legislador ordinário, ao editar o Código de Processo Civil teve a oportunidade de regulamentar o processo coletivo, porém, omitiu-se, privilegiando apenas a uniformização de jurisprudência.

Não obstante tais críticas e independente dos motivos que geraram a exclusão da temática, a melhor conclusão é entender que o Código de Processo Civil é integrante do microssistema da tutela coletiva, não apenas pela preocupação com os litígios individuais massificados e em garantir uma segurança jurídica para uniformizar as decisões proferidas em tais ações.

Não apenas isso, mas, retomando a ideia trazida anteriormente, o Código de Processo Civil traz normas aplicáveis aos processos e que influenciam diretamente nos processos coletivos, não havendo razões para sua exclusão do microssistema de tutela coletiva.

\section{A AÇÃO COLETIVA PARA PLEITEAR DIREITO INDIVIDUAL HOMOGÊNEO}


Ante a amplitude do conteúdo, resta impossível esmiuçar os detalhes deste importante Microssistema neste artigo, assim, optou-se por analisar as normas relativas às ações coletivas que tutelam direitos individuais homogêneos, regulamentadas no Capítulo II denominado: "Das ações coletivas para defesa de interesses individuais homogêneos", situado no Título II do Código de Defesa do Consumidor, em seu Artigo 9r e seguintes.

No Artigo $82^{6}$ do CDC, o legislador elencou as entidades legitimadas para propositura de tais ações coletivas, determinando a participação do Ministério Público como fiscal da lei, caso não esteja no polo ativo da demanda.

Restou disciplinado ainda a competência para propositura das ações coletivas no lugar que ocorreu ou devesse ocorrer o dano ou ainda na Capital do Estado ou Distrito Federal, caso os danos tenham repercussão regional ou nacional, bem como a competência para a execução, que será o Juízo da ação condenatória, quando a execução for coletiva ou, este Juízo ou o Juízo da liquidação da sentença, no caso de execução individual.

Um importante ponto trazido refere-se a execução das sentenças coletivas que, por serem necessariamente genéricas, necessitam de uma liquidação posterior para apuração dos danos.

A referida sentença não especifica quem são os titulares do direito e qual o valor e prestação que cada um necessita receber, possuindo um grau de generalidade maior do que aquele observado nas sentenças ilíquidas proferidas nas ações individuais.

A natureza deste tipo de sentença é alvo de divergência até mesmo pelos doutrinadores mais clássico da seara processualista. Ada Pellegrini Grinover defende que "a pretensão processual do autor coletivo, na ação de que trata o presente capítulo, é de natureza condenatória e condenatória será a sentença que acolher o pedido”. (GRINOVER, 2001, P. 813).

\footnotetext{
${ }^{6}$ Art. 82. Para os fins do art. 81, parágrafo único, são legitimados concorrentemente:

I - o Ministério Público,

II - a União, os Estados, os Municípios e o Distrito Federal;

III - as entidades e órgãos da Administração Pública, direta ou indireta, ainda que sem personalidade jurídica, especificamente destinados à defesa dos interesses e direitos protegidos por este código;

IV - as associações legalmente constituídas há pelo menos um ano e que incluam entre seus fins institucionais a defesa dos interesses e direitos protegidos por este código, dispensada a autorização assemblear.

$\S \mathrm{I}^{\circ} \mathrm{O}$ requisito da pré-constituição pode ser dispensado pelo juiz, nas ações previstas nos arts. 9r e seguintes, quando haja manifesto interesse social evidenciado pela dimensão ou característica do dano, ou pela relevância do bem jurídico a ser protegido.
} 
Em termos práticos, o mais importante é saber que toda sentença genérica proferida em sede de ação coletiva que visa a tutela de direitos individuais homogêneos necessitará de liquidação, caso o julgamento da ação seja procedente, inteira ou parcialmente.

Assim, o cumprimento de sentença será feito em duas fases distintas, sendo a liquidação destinada a trazer uma completude à fase cognitiva. Por seu turno, a fase de execução busca a satisfação do crédito anteriormente liquidado, utilizando, caso seja necessário, condutas práticas e coercitivas para efetivar o real cumprimento.

Essa liquidação e execução podem ser realizadas tanto pelas vítimas e sucessores, quanto pelos legitimados do Artigo 82 do Código de Defesa do Consumidor - legitimados para propor a ação coletiva.

Em relação aos interessados, estes podem propor execução dentro da própria ação coletiva através da sua habilitação ou ainda execuções individuais, em razão do regime de transporte in utilibus da coisa julgada coletiva para o plano individual.

Por outro lado, os legitimados do Artigo 82 podem propor as execuções coletivas em duas situações: quando não aparecer interessados suficientes em relação à gravidade do dano para evitar a impunidade do causador do dano, também chamada de Fluid Recovery ou quando o valor da indenização já tiver sido fixado em sentença de fase de liquidação.

Mostra-se interessante ressaltar que a quantidade de interessados habilitados compatível com a gravidade do dano é um conceito jurídico indeterminado e será apurado no caso concreto.

Os interessados possuem o prazo legal ${ }^{7}$ de or (um) ano para a habilitação na ação coletiva que, segundo o entendimento dominante e muitos julgados do Superior Tribunal de Justiça ${ }^{8}$, possui como termo a quo o trânsito em julgado da sentença condenatória.

Uma discussão interessante gira em torno da natureza do supramencionado prazo legal, com a presença de três correntes doutrinárias distintas. A primeira defende que o aludido prazo é decadencial, atingindo o direito material de habilitação na ação coletiva.

\footnotetext{
7 Art. 1oo. Decorrido o prazo de um ano sem habilitação de interessados em número compatível com a gravidade do dano, poderão os legitimados do art. 82 promover a liquidação e execução da indenização devida.

${ }^{8}$ Resp. 1.388.00o/PR; AgRg no AgRg no Resp. 1.169.126/RS; AgRg no Resp. I.175.o18/RS; AgRg no Resp. I.199.6oI/AP; EDcl no Resp. I.313.062/PR, entre outros julgados.
} 
Muito embora a segunda corrente defenda que a aplicação do instituto da decadência, entendem que a incidência ocorre sobre o crédito para evitar a cobrança em dobro. Uma terceira corrente - com maior número de adeptos - entende que o prazo é processual e implica na preclusão do direito à habilitação.

Em relação a litispendência e coisa julgada, o Artigo 103 do Código de Defesa do Consumidor determina que, no caso das ações que visem a tutela de direitos difusos, a sentença fará coisa julgada erga omnes, exceto quando for julgada improcedente por insuficiência de provas. No caso dos direitos coletivos stricto sensu, a coisa julgada será aplicada ultra partes, porém limitada ao grupo, categoria ou classe, possuindo a mesma exceção anteriormente explicada, quando houver insuficiência de provas.

Por seu turno, as sentenças proferidas em ações que discutem direitos individuais homogêneos fazem coisa julgada erga omnes tão somente quando houver julgamento procedente. Se julgado improcedente o pedido, aqueles que não houverem intervindo no processo na condição de litisconsortes podem propor ação de indenização a título individual.

Em relação àqueles que já haviam proposto ação individual, a legislação permite que tenha prosseguimento de forma independente e oferta uma escolha ao interessado, qual seja: requer a suspensão da ação individual em até 30 (trinta) dias após o conhecimento da ação coletiva ou seguir com a ação e não se beneficiar do resultado da ação coletiva.

Mostra-se interessante mencionar que o valor obtido com a execução coletiva propostas pelos legitimados do Art. 82 será direcionado para o Fundo de Defesa de Direitos Difusos - criado pela Lei no 7.347/85 -, conforme determinado pelo parágrafo único do Art. ıoo do Código de Defesa do Consumidor?

\section{O MODELO DE NOTIFICAÇÃO VIGENTE E SUAS CONSEQUÊNCIAS}

O processo coletivo foi criado, entre outras razões, para proteger os direitos coletivos lato sensu e propiciar uma economia processual, evitando uma multiplicidade de

\footnotetext{
${ }^{9}$ Parágrafo único. O produto da indenização devida reverterá para o fundo criado pela Lei n. ${ }^{\circ} 7.347$ de 24 de julho de 1985.
} 
ações individuais ao indicar os legitimados que terão competência para levar ao Poder Judiciário à questão massificada, pleiteando a reparação devida.

Muito embora os interessados não possam ingressar com as ações coletivas - apenas os legitimados do Art. 82 do CDC -, a participação dos mesmos ou seus sucessores mostrase de grande valia, até mesmo porque a liquidação do valor individual do dano depende da demonstração no caso concreto e individual.

O Art. 94 do Código de Defesa do Consumidor ${ }^{\text {Io }}$ determina a publicação de edital no órgão oficial após a propositura da ação coletiva visando à ciência dos interessados para, caso queiram, intervirem como litisconsortes.

$\mathrm{Na}$ segunda parte do aludido artigo, o legislador complementou que tal providência não prejudicará a divulgação por meios de comunicação pelos órgãos de defesa do consumidor.

Não obstante tal preceito, o Doutor Antonio Gidi adverte que, ao interpretar a literalidade do referido artigo, extrai-se que não há obrigatoriedade na divulgação por meios de comunicação, não havendo qualquer consequência para os órgãos que assim não proceder. Assim escreveu o supramencionado doutrinador (GIDI, 2007, p. 138):

\begin{abstract}
Se alguma entidade tiver interesse em realizar uma ampla divulgação, ela está autorizada, diz o CDC, de forma olimpicamente inútil. A lei, portanto, não diz nada: nenhum legitimado terá interesse de despender dinheiro desnecessariamente, atraindo a atenção de várias pessoas diretamente interessadas, que poderiam criticar e controlar sua atividade. Seria, sem dúvida, um "excesso de democracia". (GIDI, 2007, p. 138).
\end{abstract}

Sabe-se que em regra, os brasileiros não possuem o hábito cultural de proceder a leitura de diários oficiais - 44\% (quarenta e quatro por cento da população brasileira não tem hábito de qualquer tipo de leitura ${ }^{\mathrm{II}}$ - ou visitar os prédios onde estão instalados os fóruns para acompanhar os editais afixados nos átrios ou murais, refletindo numa baixa efetividade da medida - quase nula, diga-se de passagem - e, consequentemente, em um pequeno número de adesão dos interessados, seja através do litisconsórcio ou para promover a execução, seja ela individual ou coletiva.

\footnotetext{
${ }^{10}$ Art. 94. Proposta a ação, será publicado edital no órgão oficial, a fim de que os interessados possam intervir no processo como litisconsortes, sem prejuízo de ampla divulgação pelos meios de comunicação social por parte dos órgãos de defesa do consumidor.

${ }^{I I}$ https://www.prolivro.org.br/sa-edicao-de-retratos-da-leitura-no-brasil-2/a-pesquisa-5a-edicao/
} 
Escrito em outras palavras, observa-se que a ineficácia da informação sobre o processo coletivo não impede o grande número de ações massificadas, nem tampouco gera economia processual, além de deixar desprotegidos os direitos individuais homogêneos de tantos interessados que foram lesados e não possuem sequer o conhecimento da lesão ou que, devido ao seu grau de instrução, sentem-se inibidos em ingressar com uma ação judicial, principalmente quando as causadoras dos danos são grandes empresas com forte poder econômico.

O Doutor e Professor Antonio Gidi chegou a considerar este modelo como uma ausência completa de notificação, debilitando as ações coletivas e defendendo a inconstitucionalidade de tal norma ante a sua excessiva restrição, impossibilitando o contraditório, consoante se extra de suas palavras (GIDI, 2007, p. I42):

O direito brasileiro proporciona uma notificação insuficiente aos principais interessados no conflito objeto do processo coletivo, a ponto de poder ser considerada uma ausência total de notificação. Essa limitação do direito brasileiro enfraquece o poder político das demandas coletivas e o poder de mobilização social dos membros do grupo. A sociedade inteira sai perdendo. (GIDI, 2007, p. 142).

Dois dos pilares do princípio da inafastabilidade do Poder Judiciário - que é corolário do acesso à justiça - é a eficácia da decisão, evitando-se a ocorrência da famosa expressão popular "ganhou, mas não levou" e o princípio do contraditório efetivo.

Ao prever um meio inócuo de notificação dos participantes sobre uma ação coletiva que discute seus direitos, cria-se uma barreira de acesso à justiça pelos interessados que não possuem sequer a noção da propositura.

Ao que parece, nem sequer órgãos importantes de defesa não possuem conhecimento destas ações coletivas que estão sendo propostas perante o Judiciário, em razão da ineficácia do meio de divulgação adotado. A título de exemplo, podemos citar o Procon do Estado da Bahia - importante órgão de defesa do consumidor e com grande atuação - não tem registro de divulgação de processo coletivo em sua rede social no Instagram ${ }^{12}$ entre o período de janeiro 2017 analisado até dezembro de 2020. Em 2017, foram registradas 62.210 ações coletivas através da divulgação denominada Justiça em Números apresentada pelo Conselho Nacional de Justiça.

\footnotetext{
${ }^{12}$ https://www.instagram.com/proconbahia/
} 
Cabe frisar, não se trata de uma crítica ao Órgão de Defesa do Consumidor, mas a ausência de notificação e publicização adequada acerca da existência das demandas que envolvem os direitos individuais homogêneos para que cheguem até o público-alvo e nas entidades que atuam na defesa de tais direitos.

Noutro giro, após a leitura do Art. I03, III do $\mathrm{CDC}^{13}$, muitos poderiam questionar se realmente existiria prejuízo aos interessados, dado que a ação coletiva que visa a tutela direitos individuais homogêneos só $\mathrm{faz}$ coisa julgada erga omnes quando houver a procedência da ação, todavia, tal pensamento afasta-se novamente da ideia de economia processual, pois essa mesma ação coletiva poderia contar com mais elementos fornecidos pelos interessados em litisconsórcio, fortalecendo provas e argumentos aumentando as chances da uma sentença procedente.

Muitos defendem que houve um desestímulo por parte do legislador a participação dos interessados no processo para evitar-lhes um risco de ter que suportar os efeitos da improcedência da ação coletiva. Todavia, caso essa tenha sido a intenção, também não se coaduna com as normas fundamentais do processo civil, como o contraditório efetivo, sendo necessário que tomem ciência da existência da ação e tenha a possibilidade real de participação.

Além de esvaziar um dos propósitos da ação coletiva, o risco da improcedência pode ocorrer tanto numa ação individual quanto coletiva e, no caso de uma ampla divulgação da existência desta, maiores são as chances de o legitimado coletivo adquirir elementos para comprovar a lesão aos direitos individuais homogêneos discutidos e ao final, o processo ser julgado procedente.

O prejuízo torna-se ainda maior quando analisamos a fase de liquidação e execução da sentença coletiva. Nota-se que o Código de Defesa do Consumidor fala em expedição de edital apenas após a propositura da ação coletiva, restando omisso sobre a publicidade da sentença de procedência.

\footnotetext{
${ }^{13}$ Art. 103. Nas ações coletivas de que trata este código, a sentença fará coisa julgada:

III - erga omnes, apenas no caso de procedência do pedido, para beneficiar todas as vítimas e seus sucessores, na hipótese do inciso III do parágrafo único do art. 8I.
} 
O Código de Defesa do Consumidor, em seu artigo Ioo $^{\mathrm{I}}$, dispõe sobre a chamada fluid recovery ou reparação fluída que se configura na possibilidade dos legitimados para a propositura da ação coletiva promover a execução da sentença coletiva caso tenha decorrido or $\mathrm{ano}^{\mathrm{IS}} \mathrm{sem}$ a habilitação de interessados em número compatível com a gravidade do dano.

Muito embora seja uma solução para evitar a impunidade da pessoa causadora dos danos, não soluciona de forma eficaz a reparação financeira individual dos verdadeiros prejudicados, pois o valor indenizatório é estimado e direcionado para o Fundo de Defesa dos Direitos Difusos (FDDD) regulamentado na Lei 7.347/1985, cuja quantia, em tese, deve ser direcionada a reparação coletiva das lesões.

Cabe aqui lembrar que os direitos individuais homogêneos são acidentalmente coletivos, sendo uma opção do legislador, mas, em sua essência, é um direito naturalmente individual, com interessados específicos e danos que podem e devem ser mensurados no caso concreto.

Apresentar um processo coletivo para tutelar tais direitos e, por falta de uma notificação adequada dos interessados, destinar o valor que poderia ser utilizado para reparação das lesões individuais para um fundo, não impedirá a massificação das ações individuais, posto que os interessados, provavelmente, continuarão necessitando de uma reparação.

Cabe aqui transcrever as lições de Cássio Scarpinella Bueno que reforça que o Direito Processual serve de instrumento para atingir determinadas finalidades que deve se ajustar as suas especificidades, conforme trecho abaixo (SCARPINELLA BUENO, 2014, p. 34):

Para ser mais sintético, mas não menos exato: o processo é meio, não fim. Quando este "fim" se relaciona a conflitos de interesse regidos, no plano material, pelo direito público ou hipóteses regidas pelo direito material público, o "meio" precisa, necessariamente, ser calibrado e preparado para atingir aquele desiderato. Em suma: o processo, como meio de aplicação do direito material conflituoso, lesionado ou ameaçado, tem, necessariamente, que se adequar e se adaptar para atender às expectativas de seus fins. A tutela jurisdicional, tanto quanto a forma de prestá-la, deve ser ajustada, de uma forma ou de outra, ao direito material. É

\footnotetext{
${ }^{14}$ Art. Ioo. Decorrido o prazo de um ano sem habilitação de interessados em número compatível com a gravidade do dano, poderão os legitimados do art. 82 promover a liquidação e execução da indenização devida.

${ }^{15}$ Entende-se que deve ser contado a partir da notificação acerca do trânsito em julgado da sentença, porém, a temática é fruto de divergências doutrinárias.
} 
ele, o direito material, que justifica a razão de ser de todo o aparato jurisdicional; não o contrário. São as peculiaridades do direito material que acabam por influenciar a atuação do legislador em criar procedimentos diferenciados procedimentos especiais - para melhor viabilizar a prestação da tutela jurisdicional. (SCARPINELLA BUENO, 2014, p. 34).

O doutrinador italiano Michele Taruffo esclarece sobre o que pode ser considerado como um processo efetivo, através das seguintes palavras (TARUFFO, 2009, p. 477):

Um sistema processual é eficiente quando é razoavelmente rápido e econômico, mas também quando está estruturalmente orientado a alcançar decisões completamente informadas, corretas e confiáveis, em todos os aspectos do litígio. (TARUFFO, 2009, p. 477).

Para permitir uma melhor compreensão prática dos resultados dessa falta de notificação, utiliza-se de dois dos exemplos pensados pelo Professor Pedro Lenza para explicar os direitos individuais homogêneos, são eles: compradores de determinado carro de um lote com o mesmo defeito de fabricação ou ainda pessoas determinadas que foram contaminadas com o vírus HIV em um hospital público após transfusão de um lote de bolsas de sangue que não foram devidamente testadas. (LENZA, Pedro. 2003. p. Ioo)

Nessas duas situações, cada uma dessas pessoas amargaram danos que podem ser individualizados e quantificados. Para proporcionar a reparação desses danos e evitar outros piores utiliza-se uma ação coletiva.

Caso essas pessoas fossem devidamente notificadas por amplos meios de comunicação, poderiam participar no processo como litisconsortes e/ou liquidar dentro da própria ação coletiva seus danos individuais.

Todavia, sem a devida notificação, o processo coletivo transcorre sem participação dos interessados e, consequentemente, sem o número considerável de pessoas na fase de execução, sendo o valor direcionado para o Fundo de Defesa dos Direitos Difusos.

O aludido Fundo foi regulamentado pela Lei no 9.008/1995 que, em seu parágrafo terceiro, Art. Io determina como será utilizado o valor arrecadado:

$$
\begin{aligned}
& \S 3^{\circ} \text { Os recursos arrecadados pelo FDD serão aplicados na recuperação de bens, na } \\
& \text { promoção de eventos educativos, científicos e na edição de material informativo } \\
& \text { especificamente relacionados com a natureza da infração ou do dano causado, } \\
& \text { bem como na modernização administrativa dos órgãos públicos responsáveis pela } \\
& \text { execução das políticas relativas às áreas mencionadas no § I o deste artigo. }
\end{aligned}
$$

Ao pensar novamente nos exemplos acima citados, ainda que o valor da indenização da ação coletiva seja utilizado em algumas das situações apresentadas pela legislação, os interessados continuarão amargando seus prejuízos individuais. 
No segundo exemplo, cada pessoa contaminada precisará de cuidados específicos que demandaram maior ou menor assistência, a depender de fatores como idade, doenças, hábitos de vida, entre outros.

Ainda que o valor seja utilizado para melhoria do sistema de análises das bolsas de sangue, confecção e distribuição de informativos aos profissionais ou cursos, ainda restarão os grandes prejuízos para aqueles que foram individualmente contaminados, restando demonstrada a importância da notificação adequada dos mesmos acerca do processo coletivo e das decisões proferidas.

Outro problema envolvendo o envio do valor da indenização do processo coletivo que visa a tutela dos direitos individuais homogêneos para o citado Fundo é apontado pela Procuradora do Ministério Público Federal Mariana Guimarães de Mello Oliveira (MELLO OLIVEIRA, 2019, p. I):

\begin{abstract}
Ocorre que a União, ao longo dos anos, vem tratando os recursos do FDDD como se fossem produto de arrecadação ordinária, contingenciando cerca de $99,5 \%$ dos valores arrecadados para si, em detrimento da real destinação prevista em lei, privando, assim, a sociedade brasileira de auferir os benefícios que os projetos sociais the proporcionariam. Para se ter uma ideia, de 2011 para cá foram arrecadados quase $\mathrm{R} \$ 3$ bilhões, enquanto foram destinados ao Fundo, até o fim de 2018, cerca de $\mathrm{R} \$ 45$ milhões. (MELLO OLIVEIRA, 2019, p. I).
\end{abstract}

Os valores existentes no Fundo são objeto e litígio entre o Ministério Público Federal - MPF - e a União, através da Ação Civil Pública registrada sob o no 500813868.2017.4.03.6105, na qual o MPF defende a utilização dos recursos em conformidade com a legislação que o regulamentou.

Ao apreciar o Incidente de Suspensão de Antecipação de Tutela, o Desembargador do Tribunal Regional Federal da $3^{\text {a }}$ Região proferiu um voto-vista de 53 laudas ${ }^{16}$, momento em que chamou atenção para alguns pontos de importante reflexão sobre o fundo, entre eles: a ausência da participação dos cidadãos na destinação exata do valor e a substituição dos representantes da comunidade no Conselho por três representantes de entidades civis:

Logicamente que o referido Fundo tem um enorme arcabouço de situações a serem analisadas que fogem do objetivo deste estudo, sendo tais pontos aqui colocados com a função de demonstrar que pairam discussões sobre a utilização do valor e a gerência do

\footnotetext{
${ }^{16}$ https:// migalhas.uol.com.br/arquivos/2019/9/art20190918-18.pdf 
Fundo e reforçar a necessidade da participação dos interessados no processo coletivo que envolve direitos individuais homogêneos, permitida através de uma notificação adequada.

Por fim, mostra-se interessante destacar que o Conselho Nacional de Justiça editou a Resolução no 339 , de 08 de setembro de $2020^{17}$, disciplinando a criação do Núcleo de Ações Coletivas, do Comitê Executivo Nacional dos referidos núcleos, dos cadastros das ações coletivas nos Tribunais, bem como determinando que os Tribunais promovam a divulgação das ações coletivas em seus sítios eletrônicos, notifiquem os interessados nas ações individuais e criem especificações no protocolo da petição inicial para melhorar a comunicação aos interessados.

Muito embora seja louvável o aprimoramento interno do Poder Judiciário para trazer celeridade e, principalmente, efetividade às demandas coletivas, nota-se que não se mostram aptas a alcançar uma grande quantidade de pessoas, ante os problemas culturais relatados anteriormente, necessitando de medidas que ampliem a divulgação de tais processos para os meios de comunicação em massa utilizados atualmente.

Cabe ressaltar que entre os extremos - notificação pessoal de todos os interessados e publicação de um edital em jornal - existem inúmeras possibilidades que podem ser utilizadas, ponderando qual melhor se prestaria a sua finalidade em cada caso concreto. Nas palavras de Antonio Gidi (GIDI, 2007, p. 226):

\begin{abstract}
Quando o grupo é de tamanho reduzido, por exemplo, ou as despesas com a notificação individual não são muito elevadas, a notificação pessoal de todos os membros mostra-se uma solução adequada. É o que se pode chamar "notificação individualizada". Essa notificação, porém, não precisa ser realizada necessariamente por correio. Se o grupo é geograficamente concentrado, como os estudantes de uma escola, os trabalhadores de uma empresa ou os moradores de um bairro, nada impede que a notificação seja realizada através da entrega informal de um envelope, com ou sem a comprovação do recebimento, a critério do juiz. Quando o grupo é muito numeroso ou as despesas com a notificação pessoal são desproporcionalmente altas, porém, a melhor opção é o sampling notice, com a notificação pessoal, por amostragem, de alguns membros do grupo, se possível entre os que possuem as pretensões individuais de maior valor, e a notificação por edital dos demais. Isso seria suficiente para trazer publicidade à demanda e garantir que os membros que tomaram conhecimento efetivo da ação atuem em juízo como agentes dos interesses dos demais na tarefa de fiscalização da atividade do representante. É o que se pode chamar "notificação coletiva". (GIDI, 2007, p. 226).
\end{abstract}

Assim, na busca de contribuir com a melhoria do sistema processual coletiva, visualiza-se como algumas soluções para alcançar a efetividade destas notificações: a

\footnotetext{
${ }^{17}$ https://atos.cnj.jus.br/files/original224651202009225f6a7edbced49.pdf
} 
condenação dos causadores dos danos a fazer inserir informações nas principais mídias utilizadas pelo público alvo; a modificação do sistema de pesquisa processual para permitir a consulta das ações coletivas através de palavras chave; uma melhor divulgação por parte dos Tribunais e órgãos de defesa do consumidor, utilizando mais redes sociais, outdoors, informativos e outros métodos de maior alcance, além de realizar pesquisas junto à população ou utilizar as pesquisas existentes para aprimorar os métodos com grupos de estudos dedicados a incrementar e retirar os obstáculos, permitindo um verdadeiro acesso à Justiça.

\section{CONCLUSÃO}

A partir da análise histórica acerca das mudanças nas relações sociais, foi observada a necessidade de reconhecer os direitos que ultrapassavam o caráter individual, atingindo grupos de pessoas determinadas, bem como criar garantias para protegê-los.

O estudo liderado por Mauro Cappelletti, cujas conclusões foram chamadas de Ondas Renovatórias, teve uma grande participação na modificação da postura do Estado na forma de lidar e pensar as demandas coletivas, tendo em vista que fizeram uma exposição da ineficácia do sistema vigente à época, alertando para a necessidade de adequação do processo.

No Brasil, observou-se ainda um processo inicial lento para consagração dos direitos coletivos lato sensu, porém, com o passar do tempo, muitas legislações importantes foram criadas - a exemplo da Lei de Ação Civil Pública e o Código de Defesa do Consumidor - e servem como referência para outros países.

O presente estudo deu enfoque nos direitos individuais homogêneos, eleitos pelo legislador comum como um direito coletivo, todavia, em sua essência é um direito individual e também pode ser assim analisado, todavia, para discussão em âmbito coletivo, somente é permitida a propositura da ação pelos legitimados coletivos eleitos pela legislação.

Diante das especificidades da tutela coletiva dos direitos individuais homogêneos, chamou-se a atenção para a forma de notificação dos interessados, disposta no Artigo 94 do Código de Defesa do Consumidor, prevendo a publicação de edital no órgão oficial após 
a propositura da ação coletiva e, de forma facultativa, poderia ser divulgada a ação coletiva através dos meios de comunicação pelos órgãos de defesa do consumidor.

Entretanto, a notificação por edital possui baixa eficácia em razão da ausência de hábitos culturais do povo brasileiro, que possui um baixo índice de leitura e não possui o hábito de proceder à leitura de diários oficiais ou dirigir-se até os átrios dos órgãos públicos para verificar o que está sendo veiculado.

É grande a importância da ciência dos interessados, além de conceder-lhes possibilidade real de participação propiciando um verdadeiro acesso à justiça e coadunando-se com os objetivos e princípios do processo coletivo.

Chamou-se atenção ainda para o esvaziamento das finalidades da ação coletiva que visa à tutela dos direitos individuais homogêneos, quando os titulares desses direitos ou seus sucessores não são devidamente cientificados da existência e chamados a liquidar o julgado, não impedindo ou diminuindo as ações individuais sobre a mesma temática, bem como não reparando os danos, mesmo quando houver reparação arbitrada destinada para o Fundo dos Direitos Difusos - que, em verdade, tem servido como simples meio de arrecadação do Estado, utilizando a quantia da forma que melhor lhe convém.

Diante disso, o presente trabalho sugeriu algumas medidas que podem ser adotadas para proporcionar a melhoria dessa comunicação, tais como: a condenação dos causadores dos danos a veicular informações nas principais mídias utilizadas pelo público alvo; a modificação do sistema de pesquisa processual para permitir a consulta das ações coletivas através de palavras chave; uma melhor divulgação por parte dos Tribunais e órgãos de defesa do consumidor, construir grupos de estudos dedicados a incrementar e retirar os obstáculos, rumo ao verdadeiro acesso à Justiça.

Essas ações devem ser realizadas de forma conjunta, incluindo o Poder Legislativo aprimoramento de leis -, o Poder Executivo - utilizando o orçamento de forma eficaz e ajustando os métodos de notificação para que atinjam o máximo de interessados possíveis, o Poder Judiciário - melhorando a divulgação das ações coletivas, determinando medidas, através do seu poder geral de cautela, bem como todas as entidades e órgãos de defesa dos direitos individuais homogêneos.

\section{REFERÊNCIAS}


ABELHA, Marcelo. Ação Popular. Ações Constitucionais. Organizador: Fredie Didier Jr. Salvador: Jus Podium, 2006.

ANDRADE, Adriano; MASSON, Cleber; ANDRADE, Landolfo. Interesses difusos e coletivos esquematizado. 5. ed. rev., atual. e ampliada - Rio de Janeiro: Forense; São Paulo: MÉTODO, 2015.

BASTOS. Fabrício Rocha. Do Microssistema da Tutela Coletiva e a Sua Interação com o CPC/2015. Revista do Ministério Público do Rio de Janeiro no 68, abr./jun. 2018. Disponível em

http://www.mprj.mp.br/documents/20184/1242829/Fabricio_Rocha_Bastos.pdf.

BESSA, Leonardo Roscoe; BENJAMIN, Antônio Herman Vasconcellos;

MARQUES, Cláudia Lima. Manual de Direito do Consumidor. São Paulo: RT, 2007.

BONAVIDES, Paulo. Curso de direito constitucional. ı8. ed. São Paulo: Malheiros, 2006.

BRASIL. Conselho Nacional de Justiça. Plataforma do CNJ: Justiça em Números. Disponível em http://www.cnj.jus.br/pesquisas-judiciarias/paineis.

BRASIL. Conselho Nacional de Justiça. Resolução no 339 de 8 de setembro de 2020 . Disponível em https://atos.cnj.jus.br/files/original224651202009225f6a7edbced49.pdf.

BRASIL. Glossário de Termos Jurídicos. Ministério Público Federal. Disponível em http://www.mpf.mp.br/es/sala-de-imprensa/glossario-de-termos-juridicos\#N.

BRASIL. Portal da Legislação. Planalto. Disponível em http://www4.planalto.gov.br/legislacao/.

BRASIL. Superior Tribunal de Justiça. Recurso Especial no 911802, Rio Grande do Sul. Recorrente: Brasil Telecom S/A. Recorrido: Associação Nacional dos Usuários do Sistema 
Fixo Comutado e Móvel Celular - ANUSTEL. Relator: Ministro José Delgado. Brasília, DF, 24 de outubro de 2007.

BUENO, Cassio Scarpinella. Curso sistematizado de direito processual civil: direito processual público, direito processual coletivo, vol. 2, tomo III - 4. ed. rev. e atual. - São Paulo: Saraiva, 2014.

CAPPELlETTI, Mauro. Acesso à Justiça. Tradução Ellen Gracie Northfleet. Porto Alegre: Sergio Antonio Fabris Editora. 1989.

CARVALHO, Fernando. O Princípio da Eficiência no Processo Coletivo - Constituição, Microssistema de Tutela Coletiva e Novo Código de Processo Civil. In: ZANETI JUNIOR, Hermes (Org.). Coleção Repercussões do Novo CPC: Processo Coletivo. Salvador: Juspodivm, 2016.

GARTH, Bryant; CAPPELLETI, Mauro. Acesso à justiça. Porto Alegre: Fabris, 1988.

GAVRONSKI, Alexandre Amaral. Autocomposição no novo CPC e nas Ações Coletivas. Processo Coletivo. In: ZANETI JUNIOR, Hermes (Org.). Coleção Repercussões do Novo CPC: Processo Coletivo. Salvador: Juspodivm, 2016.

GIDI, Antonio.A Class Action como instrumento de tutela coletiva de direitos. São Paulo: RT, 2007.

GOVERNO DA BAHIA. Programa de Proteção e Defesa do Consumidor - PROCON BAHIA. Rede Social: Instagram, acesso disponível em https://www.instagram.com/proconbahia/.

INSTITUTO PRÓ LIVRO. $5^{\text {a }}$ edição da Retratos da Leitura no Brasil com acesso disponível em https://www.prolivro.org.br/sa-edicao-de-retratos-da-leitura-no-brasil-2/apesquisa-5a-edicao/. 
JAVORSKI, Carlos Vinicius. Repercussões do novo código de processo civil no microssistema de tutela coletiva: normas fundamentais e tutela dos direitos individuais homogêneos. 2017.

Disponível em https://riuni.unisul.br/bitstream/handle/ı2345/6500/CARLOS_VINICIUS_JAVORSKI$\% 5 B 44762-11289-1-633713 \% 5$ DTCC_-_FINAL__Carlos_Vinicius_Javorski.pdf?sequence $=\mathrm{I} \&$ is Allowed $=\mathrm{y}$.

MANCUSO, Rodolfo de Camargo. Jurisdição Coletiva e Coisa Julgada. Teoria Geral das Ações Coletivas. São Paulo: Editora Revistas dos Tribunais, 2006.

MELlO OlIVEIRA, Mariana Guimarães. A Sociedade e o Fundo de Direitos Difusos. 2019. Sítio eletrônico do Ministério Público Federal, disponível em http://www.mpf.mp.br/go/institucional/publicacoes/, acesso em 02/02/2021.

NEVES, Daniel Amorim Assumpção. Manual do Processo Coletivo: volume único. $4^{\underline{a}}$ ed. rev., atualizada e ampliada Salvador: Ed. Juspodivm, 2020.

ROQUE, André Vasconcelos. As ações coletivas após o novo Código de Processo Civil: para onde vamos? In: ZANETI JUNIOR, Hermes (Org.). Coleção Repercussões do Novo CPC: Processo Coletivo. Salvador: Juspodivm, 2016.

THEODORO JÚNIOR, Humberto. Curso de Direito Processual Civil - Teoria geral do direito processual civil, processo de conhecimento e procedimento comum - vol. I. 56. ed. revista atual e ampl. - Rio de Janeiro: Forense, 2015.

ZANETI JUNIOR, Hermes. Direitos coletivos lato sensu: a definição conceitual dos direitos difusos, dos direitos coletivos stricto sensu e dos direitos individuais homogêneos. Disponível em http://www.abdpc.org.br/artigos/artigor4.htm. 
ZAVASCKI, Teori Albino. Processo Coletivo: Tutela de Direitos Coletivos e Tutela Coletiva de Direitos. Porto Alegre, setembro de 2005. 